Article

\title{
Biodegradable Polycaprolactone-Titania Nanocomposites: Preparation, Characterization and Antimicrobial Properties
}

Alexandra Muñoz-Bonilla ${ }^{1, *}$, María L. Cerrada ${ }^{1, \dagger}$, Marta Fernández-García ${ }^{1, \dagger}$, Anna Kubacka ${ }^{2, *}$, Manuel Ferrer ${ }^{2, \dagger}$ and Marcos Fernández-García ${ }^{2, \dagger}$

1 Instituto de Ciencia y Tecnología de Polímeros (ICTP-CSIC), C/Juan de la Cierva 3, 28006 Madrid, Spain; E-Mails: mlcerrada@ictp.csic.es (M.L.C.); martafg@ictp.csic.es (M.F.-G.)

2 Instituto de Catálisis y Petroleoquímica, (ICP-CSIC), C/Marie Curie 2, 28049 Madrid, Spain; E-Mails: mferrer@icp.csic.es (M.F.); mfg@icp.csic.es (M.F.-G.)

$\dagger$ These authors contributed equally to this work.

* Authors to whom correspondence should be addressed; E-Mails: sbonilla@ictp.csic.es (A.M.-B.); ak@icp.csic.es (A.K.); Tel.: +34-91-5622900 (ext. 331) (A.M.-B.); +34-91585939 (A.K.); Fax: +34-91-5644853 (A.M.-B.); +34-91-5854760 (A.K.).

Received: 27 March 2013; in revised form: 11 April 2013 / Accepted: 16 April 2013 /

Published: 29 April 2013

Abstract: Nanocomposites obtained from the incorporation of synthesized $\mathrm{TiO}_{2}$ nanoparticles $(\approx 10 \mathrm{~nm}$ average primary particle size $)$ in different amounts, ranging from 0.5 to 5 wt. $\%$, into a biodegradable polycaprolactone matrix are achieved via a straightforward and commercial melting processing. The resulting nanocomposites have been structurally and thermally characterized by transmission electron microscopy (TEM), wide/small angle X-ray diffraction (WAXS/SAXS, respectively) and differential scanning calorimetry (DSC). TEM evaluation provides evidence of an excellent nanometric dispersion of the oxide component in the polymeric matrix, with aggregates having an average size well below $100 \mathrm{~nm}$. Presence of these $\mathrm{TiO}_{2}$ nanoparticles induces a nucleant effect during polymer crystallization. Moreover, the antimicrobial activity of nanocomposites has been tested using both UV and visible light against Gram-negative Escherichia coli bacteria and Gram-positive Staphylococcus aureus. The bactericidal behavior has been explained through the analysis of the material optical properties, with a key role played by the creation of new electronic states within the polymer-based nanocomposites. 
Keywords: titania; polycaprolactone; nanocomposites; thermal properties; antimicrobial

\section{Introduction}

Food packaging plays a decisive role in achieving protection and preservation of all types of food, particularly from oxidative and microbial spoilage, as well as dehydration and, therefore, extends the shelf life of the food product. Synthetic and non-biodegradable materials are most often used for food packaging and accumulation of which poses a threat to the environment. The most effective solutions to promote both food and environment preservation, in this type of packaging might comprise, on one hand, the replacement of such materials for other environmentally friendly packaging ones based, for instance, on biodegradable polymers, and, on the other hand, the incorporation of some antimicrobial agent that minimizes and even prevents the growth and adhesion of detrimental microorganisms. Concerning the former aspect, poly( $\varepsilon$-caprolactone), PCL, which is a semicrystalline linear aliphatic polyester, could be a good candidate. Additional characteristics that can be mentioned include its flexibility, non-toxicity, hydrophobicity and ease to be processed [1-3]. Related to the second point, titania might be an excellent alternative. $\mathrm{TiO}_{2}$ is an inert and cheap material, and its well-known non-toxicity (even in nanometric scale) for human related applications allows its use as an additive in cosmetics, pills or toothpaste [4]. Additionally, $\mathrm{TiO}_{2}$ is able to eliminate (within an extended period of time) dead cells, rendering $\mathrm{CO}_{2}$, opening, in this way, a path for the auto-regeneration of the system [5-7]. A point of relevance is the control of the $\mathrm{TiO}_{2}$ polymorphism ensuring the presence of the anatase form, the one with the highest biocidal capability, as well as to control primary particle size in the nanometer range, a fact that would limit scattering events among other things $[8,9]$. $\mathrm{TiO}_{2}$-anatase works under UV light excitation with energy above the corresponding band gap ( $c a .3 .2 \mathrm{eV}$ ), forming energy-rich electron-hole pairs. Such charge carriers are able to interact with microorganisms, rendering biocidal properties to the corresponding polymer-based nanocomposite films [10-13].

Organo-inorganic nanocomposite materials that combine attractive qualities of dissimilar oxide and polymer components are not simply physical blends, but they can be broadly defined as complex materials containing both organic and inorganic constituents intimately mixed. The scale of mixing or, in other words, the degree of homogeneity, would influence or even command the ultimate properties of the solid nanocomposite materials when the component mixture is adequately reached, typically at the nanometer range $[14,15]$. In particular, the optimization of the component contact has been shown to be crucial in order to render $\mathrm{TiO}_{2}$-containing polymer nanocomposites with outstanding biocidal properties $[10-13,16,17]$. All these together features might lead to a safer, cost-effective technology of general application as an alternative to current inorganic- and organic-based biocidal agents.

The goal of this work is, then, to gain knowledge on the universality of using $\mathrm{TiO}_{2}$-anatase nanoparticles to impart antimicrobial characteristics in polymer-based nanocomposites. An efficient organo-inorganic contact has been previously proved to change the nature of the $\mathrm{TiO}_{2}$ agent, avoiding the requirement of a close proximity with the pathogen and making the oxide in the nanocomposite a non-contact agent [17]. Then, the preparation and complete characterization of polycaprolactone- $\mathrm{TiO}_{2}$ nanocomposites are here reported. Several contents of the inorganic component have been evaluated, 
and a comprehensive structural characterization of the different organic-inorganic nanocomposites has been performed because of the feasible effect of $\mathrm{TiO}_{2}$ on the polymeric structural details (crystallinity, crystal size, melting and crystallization temperatures) and, consequently, on the overall physical properties. Therefore, through a multi-technique approach, the study aims to show that adequate incorporation of $\mathrm{TiO}_{2}$ into a biodegradable PCL leads to a powerful antimicrobial system, with a biocidal potential higher than that of the oxide alone.

\section{Results and Discussion}

The polycaprolactone is semicrystalline and wide angle X-ray diffraction (WAXS) experiments were performed to determine the influence of $\mathrm{TiO}_{2}$ nanoparticle incorporation on the crystal lattice developed in the different nanocomposites. Similar WAXS profiles are found from room temperature to the molten state for all the hybrid samples and the PCL polymeric component, as depicted in Figure 1. Therefore, all of these quenched specimens show an orthorhombic lattice, without noticeable changes with respect to the profile exhibited by the neat PCL. In addition to the rather constant 110 and 200 diffraction peaks characteristic of the PCL orthorhombic cell [18], the 101 reflection ascribed to the $\mathrm{TiO}_{2}$ anatase polymorph (centered at $c a$. $25^{\circ}$; JCPDS-84-1286) is seen in the nanocomposites and its intensity increases as the $\mathrm{TiO}_{2}$ content does. The crystallinity degree of the different nanocomposites can be estimated from these WAXS patterns by their decomposition into crystalline diffractions and the amorphous component, since the amorphous halo is not known at a given temperature (it is only characterized in the molten state). The amorphous peak of the different samples was found at room temperature to be centered at $2 \theta=19.8 \pm 0.2$ after deconvolution. Its position can be undoubtedly determined after the melting process has taken place. Values are listed in Table 1 and show that position of the most probable intermolecular distance between PCL macromolecules $\left(d^{\mathrm{HALO}}\right)$ is slightly moved to higher spacing values with increasing $\mathrm{TiO}_{2}$ content. Variation is subtle, but seems to indicate that favorable PCL- $\mathrm{TiO}_{2}$ interactions are being created, at least, in the molten state, and these interactions weaken those existing between polymeric macromolecules. Table 1 also reports the crystallinity results calculated at room temperature. It is clearly observed that this magnitude remains nearly unchanged by the presence of $\mathrm{TiO}_{2}$ nanoparticles.

Figure 1. Real-time variable-temperature wide angle X-ray diffraction (WAXS) profiles obtained with synchrotron radiation for all the samples in a melting experiment at $8{ }^{\circ} \mathrm{C} / \mathrm{min}$. From left to right: $\mathrm{PCL}-\mathrm{TiO}_{2}-0 ; \mathrm{PCL}^{-T i O}{ }_{2}-05 ; \mathrm{PCL}_{-} \mathrm{TiO}_{2}-1 ; \mathrm{PCL}_{-} \mathrm{TiO}_{2}-2$ and PCL-TiO 2 -5. PCL, poly( $\varepsilon$-caprolactone).

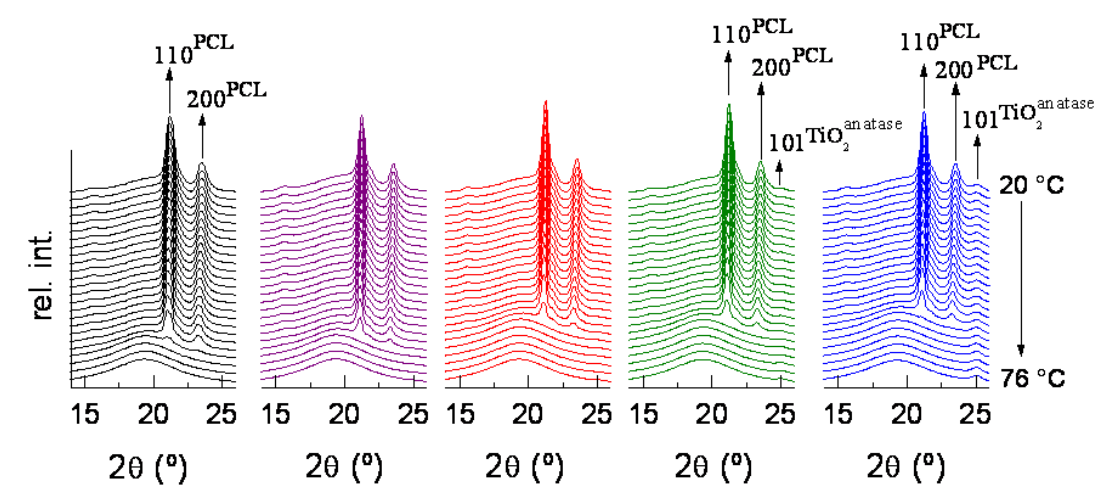


Table 1. Characteristics of the PCL crystalline phase for the different nanocomposites and for the pristine PCL homopolymer: $f_{c}{ }_{\text {NARM }}$ (crystallinity degree determined by WAXS at room temperature); $d^{\mathrm{HALO}}$ (spacing of the amorphous halo in the molten state); $L^{\mathrm{SAXS}}$ (long spacing estimated by small angle X-ray diffraction (SAXS) at room temperature) and $l_{c}$ (most probable crystal size calculated assuming a two-phase model: $l_{\mathrm{c}}=L^{\mathrm{SAXS}} \times f_{c}^{\mathrm{NORM}}$ WAXS.

\begin{tabular}{|c|c|c|c|c|c|}
\hline Specimen & $\mathrm{TiO}_{2}$ wt.\% & $f_{c}^{\text {NORM }}{ }_{\text {WAXS }}$ & $d^{\mathrm{HALO}}(\mathrm{nm})$ & $L^{\mathrm{SAXS}}(\mathrm{nm})$ & $l_{c}(\mathrm{~nm})$ \\
\hline PCL-TiO ${ }_{2}-0$ & 0.0 & 0.53 & 0.448 & 15.8 & 8.4 \\
\hline $\mathrm{PCL} \mathrm{TiO}_{2}-05$ & 0.5 & 0.54 & 0.448 & 15.8 & 8.5 \\
\hline PCL-TiO ${ }_{2}-1$ & 1.0 & 0.54 & 0.449 & 16.1 & 8.7 \\
\hline $\mathrm{PCL}^{-\mathrm{TiO}_{2}-2}$ & 2.0 & 0.53 & 0.449 & 16.1 & 8.5 \\
\hline PCL-TiO ${ }_{2}-5$ & 5.0 & 0.53 & 0.450 & 16.0 & 8.5 \\
\hline
\end{tabular}

Real time variable-temperature SAXS experiments were also performed to estimate long spacing values and the effect of $\mathrm{TiO}_{2}$ incorporation. PCL-TiO $2-0$ profiles, as well as those represented in the distinct insets of Figure 2 show the initial profiles during heating for all of the samples analyzed. Several characteristics are common independently of $\mathrm{TiO}_{2}$ content: (a) an important shift of the peak to lower $s$ values (i.e., a rise of long spacing, $L^{\mathrm{SAXS}}$, since $s=1 / d$ and $d=L^{\mathrm{SAXS}}$ ) with increasing temperature and this fact indicating changes in the PCL lamellar thickness, in its amorphous layer thickness or in both of them; (b) the existence of a periodicity peak after melting of the polymeric matrix in all the nanocomposites (see the insets in Figure 2 for the distinct hybrids). This correlation peak is ascribed to a characteristic spacing between $\mathrm{TiO}_{2}$ nanoparticles [19]. Therefore, two specific contributions should be initially taken into consideration: the one associated with differences in electronic density between crystallites and amorphous regions in the PCL component and that regarding the presence of $\mathrm{TiO}_{2}$ in the resulting materials.

To exclusively evaluate the characteristics of the PCL crystallites, the latest contribution has been subtracted, as depicted in the patterns represented in Figure 2. Then, values of the most probable long spacing can be deduced from these Lorentz-corrected SAXS profiles [20-22] and those found at room temperature are reported in Table 1. A slight increase of the long spacing is detected, a fact that seems to point out that slightly thicker PCL crystallites are developed in the nanocomposites with respect to those existing in the pristine PCL matrix. To confirm this statement, the most probable crystallite size in the direction normal to the lamellae, $l_{\mathrm{c}}$, has been determined by assuming a simple two-phase model, i.e., $l_{\mathrm{c}}=L^{\mathrm{SAXS}} \times f_{c}{ }^{\mathrm{NORM}}{ }_{\text {WAXs }}$. The values attained are also listed in Table 1 , showing very small differences between specimens.

The crystalline nature of these nanocomposites can be also evaluated from calorimetric measurements (see Figure 3a,b for first melting and crystallization processes, respectively). Two endothermic processes take place during the first heating run, the former one at very low temperatures ascribed to the glass transition (see inset in Figure 3a) and that related to the melting of crystallites at higher temperatures. Glass transition temperature, $T_{g}$, remains rather constant independently of the $\mathrm{TiO}_{2}$ content (values reported in Table 2), a feature that indicates that mobility within the PCL amorphous regions does not vary much with $\mathrm{TiO}_{2}$ incorporation. On the other hand, the initial melting 
process shows multiple melting stages, since the crystalline phase transitions of PCL samples strongly depends on thermal history. Then, melting peaks from the DSC traces vary for samples stored at room temperature for different periods of time, and long-term maintained samples usually exhibit higher melting temperature. This fact implies that there is a progress of the crystalline structure at room temperature in the PCL-based samples, because of its low glass transition temperature, although it occurs at a rather slow pace. This feature is clearly deduced when comparing the first melting curves (Figure 3a) with those coming from the second heating run (inset in Figure 3b). Accordingly, melting temperature and crystallinity are, at a given specimen after a week at room temperature, higher than the ones attained just after crystallization, in spite of the cooling rate imposed in the initial film processing being much faster than the one applied along calorimetric measurement. This structural evolution makes it necessary to be very careful with these samples. Therefore, the PCL-based specimens must have an identical and well-defined thermal protocol (time elapsed from their processing and storage temperature) in order to obtain reproducible and reliable results.

Figure 2. Real-time variable-temperature Lorentz-corrected SAXS profiles (main plots: only the polymeric contribution; insets: initial patterns in the nanocomposites: $\mathrm{TiO}_{2}$ and polymeric contributions) obtained with synchrotron radiation for all the samples as processed in a melting experiment from 20 to $76^{\circ} \mathrm{C}$ at $8{ }^{\circ} \mathrm{C} / \mathrm{min}$.

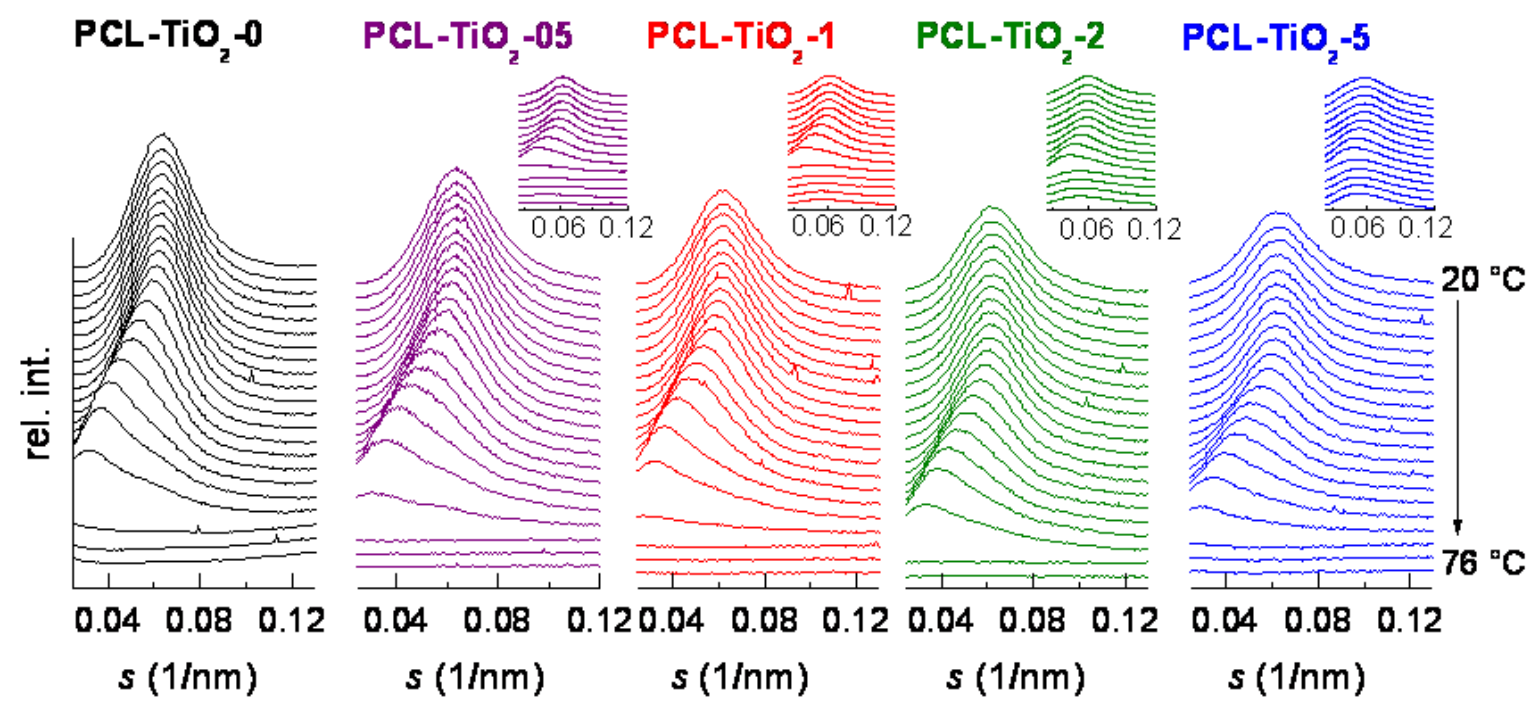

This multiple melting behavior in polymers has been explained by assuming successive melting-recrystallization processes [23-26], existence of dual lamellar populations [27,28] or presence of two or more polymorphs [29-32]. The former assumption seems to be the cause for this thermal response in the specimens under study, since a unique PCL crystalline structure is developed, as deduced from WAXS measurements and two crystallite populations have not been apparently observed, as revealed in the SAXS profiles within the temperature range of interest. Consequently, melting of smallest and thinnest crystals takes place at low temperatures, and this molten material undergoes continuous recrystallization-melting phenomena with increasing temperature to form larger and thicker lamellae that melt at higher temperatures. Table 2 shows similar melting temperatures in the pristine PCL and the different nanocomposites, these results being in agreement with the rather analogous values of most probable crystal size deduced from combination of WAXS and SAXS measurements. 
Figure 3. DSC curves corresponding to: (a) the first heating process and (b) the crystallization corresponding to the pristine PCL homopolymer and its nanocomposites with distinct $\mathrm{TiO}_{2}$ nanoparticle contents. The insets in (a) and (b) plots are related to the glass transition region and to the subsequent heating run after crystallization process, respectively.
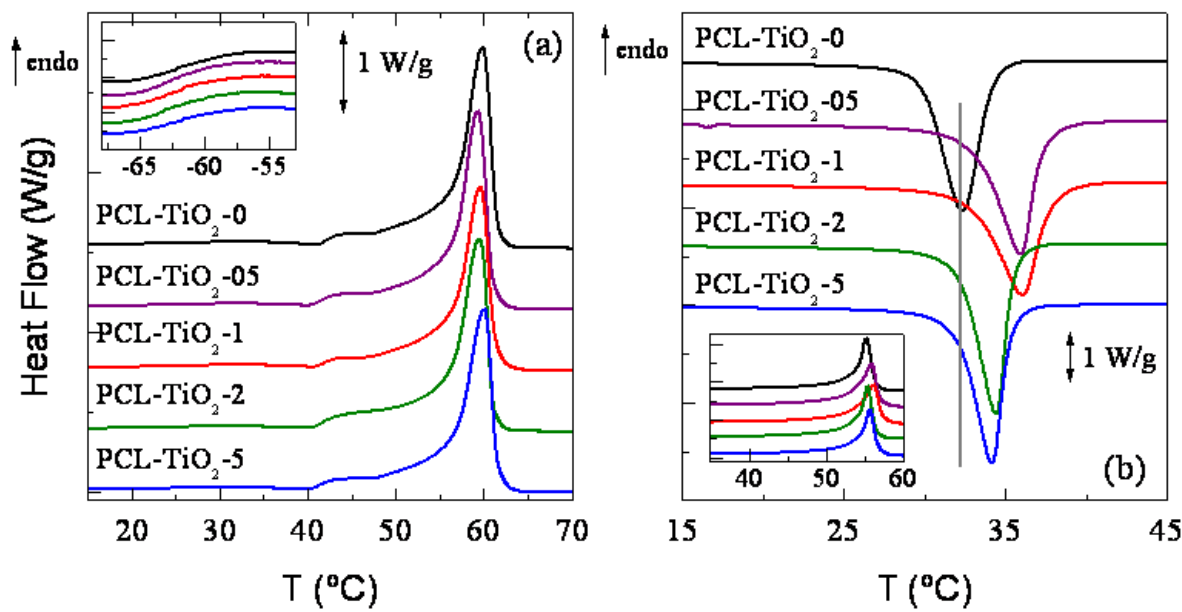

Table 2. Phase transition temperatures: glass transition temperature $\left(T_{g}\right)$, melting temperature $\left(T_{m}{ }^{\mathrm{F} 1}\right.$ and $T_{m}{ }^{\mathrm{F} 2}$, first and second melting processes, respectively) and crystallization temperature $\left(T_{c}\right)$; normalized crystallinities (first and second melting processes, as well as crystallization: $f_{c}^{\mathrm{NORM}}{ }_{\mathrm{F} 1}, f_{c}^{\mathrm{NORM}}{ }_{\mathrm{F} 2}$ and $f_{c}^{\mathrm{NORM}}{ }_{\mathrm{C}}$, respectively) ${ }^{\mathrm{a}}$.

\begin{tabular}{|c|c|c|c|c|c|c|c|}
\hline Specimen & $T_{g}\left({ }^{\circ} \mathrm{C}\right)$ & $f_{c}^{\text {NORM }}{ }_{\mathrm{F} 1}$ & $T_{m}{ }^{\mathrm{F} 1}\left({ }^{\circ} \mathrm{C}\right)$ & $f_{c}{ }^{\mathrm{NORM}}{ }_{\mathrm{C}}$ & $T_{c}\left({ }^{\circ} \mathrm{C}\right)$ & $f_{c}^{\text {NORM }}$ & $T_{m}{ }^{\mathrm{F} 2}\left({ }^{\circ} \mathrm{C}\right)$ \\
\hline PCL-TiO ${ }_{2}-0$ & -60.0 & 0.68 & 60.0 & 0.47 & 32.5 & 0.59 & 55.0 \\
\hline PCL-TiO -05 & -60.5 & 0.66 & 59.5 & 0.47 & 36.0 & 0.59 & 55.5 \\
\hline PCL-TiO $2-1$ & -60.5 & 0.66 & 59.5 & 0.46 & 36.0 & 0.58 & 56.0 \\
\hline $\mathrm{PCL}^{-\mathrm{TiO}_{2}-2}$ & -60.0 & 0.66 & 59.5 & 0.47 & 34.5 & 0.59 & 55.5 \\
\hline${\mathrm{PCL}-\mathrm{TiO}_{2}-5}$ & -60.0 & 0.65 & 60.0 & 0.46 & 34.0 & 0.58 & 55.5 \\
\hline
\end{tabular}

${ }^{\mathrm{a}}$ Estimated errors: temperatures $\pm 0.5^{\circ} \mathrm{C}$; crystallinity $\pm 5 \%$.

Enthalpy of melting can be also determined from these melting curves, and consequently, the DSC crystallinity can be estimated if the enthalpy of melting for the $100 \%$ crystal is previously known. A value of $135 \mathrm{~J} \mathrm{~g}^{-1}$ has been considered [33,34], and the results obtained after normalizing by the actual PCL amount at each hybrid are reported in Table 2. There is not considerable variation in the degree of crystallinity developed in the different samples, as already observed from the values calculated at room temperature from WAXS patterns. Nevertheless, the DSC values are greater than those determined from WAXS profiles, since part of the material in amorphous state at room temperature is able to crystallize during the heating processes and contribute to the final degree of ordering.

Figure $3 \mathrm{~b}$ shows the PCL crystallization process for the different samples. It is clear the nucleating effect that $\mathrm{TiO}_{2}$ nanoparticles has on the PCL matrix. Consequently, crystallization temperatures, $T_{c}$, are moved to higher values (see Table 2). The influence as nucleant that $\mathrm{TiO}_{2}$ exerts seems to be slightly dependent on the content, and thus, a less significant effect is observed as $\mathrm{TiO}_{2}$ incorporation is increased in the nanocomposite. This shift of $T_{c}$ is not related to a variation of crystallinity, but most probable crystallite size is, however, slightly enlarged as deduced from values estimated from SAXS and from the subsequent melting temperatures, $T_{m}{ }^{\mathrm{F} 2}$. 
To gain knowledge on how inorganic component is arranged within the PCL matrix, because of its impact in the final performance of the resulting materials, TEM analysis was carried out. Figure 4 shows a uniform dispersion of inorganic nanoparticles within the polymer for the $\mathrm{PCL}-\mathrm{TiO}_{2}-2$ nanocomposite and the non-existence of $\mathrm{TiO}_{2}$ aggregates of a large size. This behavior parallels the one observed in the other $\mathrm{TiO}_{2}$-based nanocomposite systems [12,13,16,17] prepared by melting processing. The oxide is dispersed in the polymeric matrix exhibiting nanometer-scale aggregates ranging from 10 (the oxide primary particle size) to $180 \mathrm{~nm}$, with an average size (Feret diameter) [35] of $c a .80 \mathrm{~nm}$. The nanometric dispersion of the oxide attained in the loadings analyzed up to $5 \mathrm{wt} . \%$ is significant, considering that the titania preparation makes use of an oxide previously calcined at high temperature to ensure the exclusive presence of the anatase polymorph and, then, a strict control of its biocidal properties.

Figure 4. TEM micrographs of the $\mathrm{PCL}-\mathrm{TiO}_{2}-2$ nanocomposite.

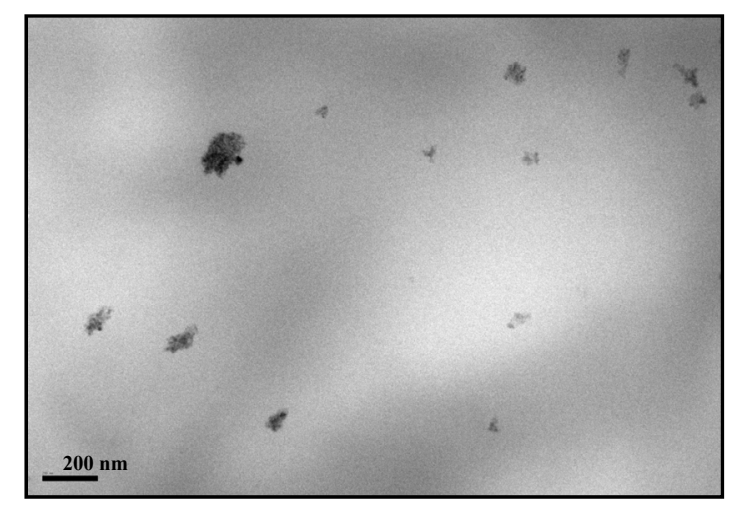

Incorporation of well-dispersed nanoparticles within polymeric matrices has been proved to induce, sometimes, thermal degradation of the final materials. Accordingly, a very significant catalytic effect has been reported in hybrids based on Al nanoparticles within a poly(vinylidene fluoride) (PVDF) matrix [36], either under inert or oxidant atmospheres and an important shift of degradation temperatures, around $100{ }^{\circ} \mathrm{C}$ down to that found in the pristine matrix, even at a content as low as 1.5 wt.\%. Mesoporous MCM-41 silica has promoted the thermal decomposition of hybrids based on polyethylene [37]. Nevertheless, incorporation of $\mathrm{Cu}$ nanoparticles into PVDF maintained and even slightly delayed the primary thermal decomposition in experiments performed under inert conditions [38]. Addition of $\mathrm{TiO}_{2}$ has displayed different effects depending on the polymeric matrix in which it is incorporated: a considerable catalytic effect in nanocomposites based in ethylene-vinyl alcohol (EVOH) copolymer or an almost null action in polypropylene [39,40]. Figure 5 shows the results related to the thermal stability of these PCL-based nanocomposites under inert and oxidant conditions. Looking first at curves achieved under a nitrogen atmosphere (Figure 5a), it can be said that degradability is nearly not affected by incorporation of oxide nanoparticles and, moreover, decomposition seems to take place in a unique stage (Figure 5b). Only, the onset temperature of decomposition is slightly moved to lower temperature. This picture is somehow different to that obtained when thermal stability is evaluated under an oxidant environment (Figure 5c). In this case, the degradation mechanism is more complex and takes place in several stages (Figure 5d). In addition, the presence of $\mathrm{TiO}_{2}$ nanoparticles slightly favors degradability, and the temperature of maximum 
degradation is shifted toward values lower than that corresponding to the PCL homopolymer. Nevertheless, the onset of degradation in the nanocomposites is moved to higher temperatures about $20{ }^{\circ} \mathrm{C}$, this means that the beginning of the degradation process is a little postponed with the incorporation of $\mathrm{TiO}_{2}$ under air conditions. On the other hand, the $\mathrm{TiO}_{2}$ content can be estimated from the residual mass at the end of the experiments. A good agreement was found when comparing the averaged values with the theoretical loadings: $0.4 \%, 1.0 \%, 2.3 \%$ and $4.5 \%$ for the $\mathrm{PCL}-\mathrm{TiO}_{2}-05$, PCL-TiO $2-1$, PCL-TiO $2-2$ and $\mathrm{PCL}-\mathrm{TiO}_{2}-5$, respectively.

Figure 5. Left plot: (a) TG and (b) DTG curves obtained under an inert atmosphere; right plot: (c) TG and (d) DTG curves obtained under an oxidant atmosphere of pristine PCL homopolymer and the different nanocomposites analyzed. DTG curves have been vertically shifted for clarity.

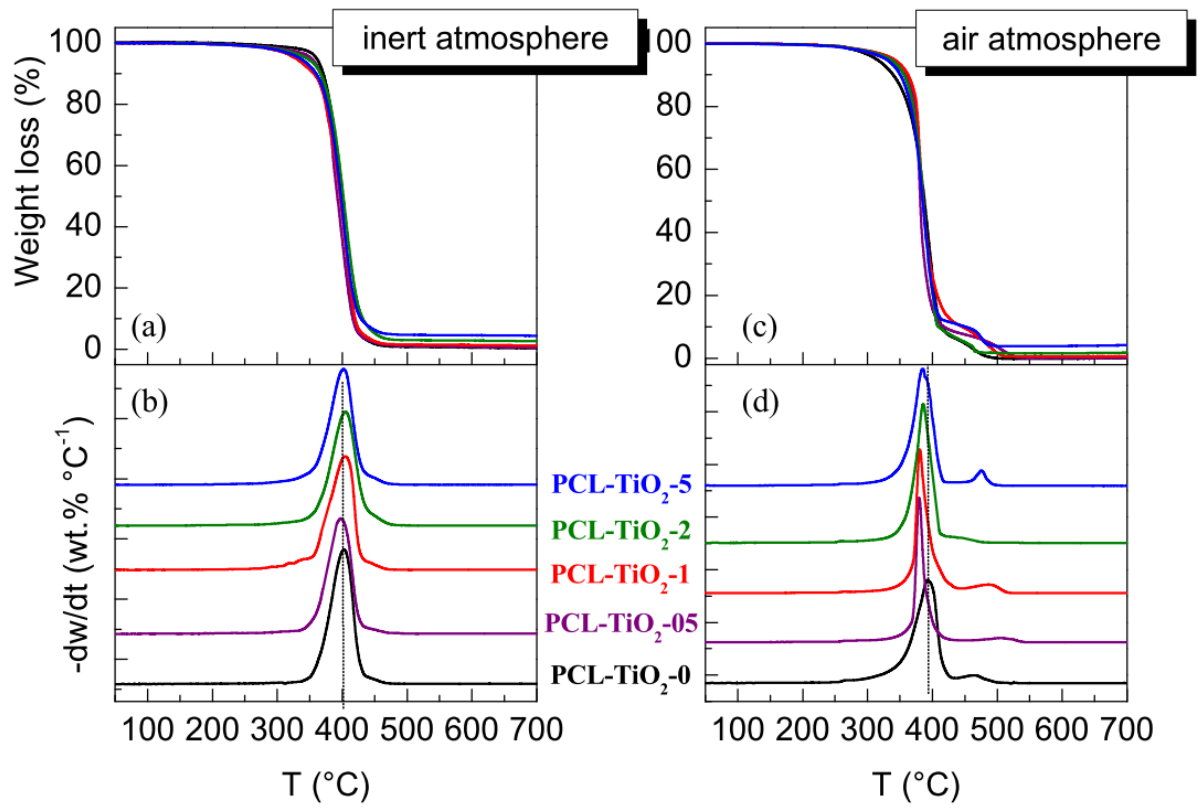

The presence of $\mathrm{TiO}_{2}$ in these nanocomposites has revealed non-significant changes in the PCL crystalline structure, phase transitions and thermal stability. Nevertheless, a more critical aspect is the knowledge of the effect of $\mathrm{TiO}_{2}$ on their optical properties, since they are rather important considering the need of efficient light absorption by $\mathrm{TiO}_{2}$ to become a biocidal material. The spectrum of the $\mathrm{TiO}_{2}$ component has been reported elsewhere [8,9,41] and is characterized by a band gap of $3.2 \mathrm{eV}$ (ca. $380 \mathrm{~nm}$ ). The UV-visible spectra of the nanocomposites and reference PCL are displayed in Figure 6. The PCL polymeric component shows a weak shoulder at $250-300 \mathrm{~nm}$, which is attributed to the $n \rightarrow \pi^{*}$ transition of the ester carbonyl. Incorporation of the inorganic component to the PCL polymeric matrix leads to important changes in the absorption profile. Inorganic nanoparticle loadings below 2 wt.\% mainly alter the PCL spectrum by enhancing the absorbance on the visible region. Changes are more dramatic at 5 wt.\% content and a new, broad absorption feature between 330 and $400 \mathrm{~nm}$ becomes evident. Therefore, presence of the inorganic component has two effects: enhancement of the signal intensity in the UV-A and visible ranges and indication of the characteristic oxide band gap. This last feature is only clearly distinguishable in the sample with the highest $\mathrm{TiO}_{2}$ content $\left(\mathrm{PCL}-\mathrm{TiO}_{2}-5\right)$. Light interaction with the nanocomposite materials would thus display a complex 
behavior, with an improvement of the absorption power of the nanocomposite that is not easily ascribed to any of the bare components, this being particularly true in the visible region because neither of them absorb light.

Figure 6. UV-visible absorption spectra of the PCL component and $\mathrm{PCL}-\mathrm{TiO}_{2}-x$ nanocomposite materials.

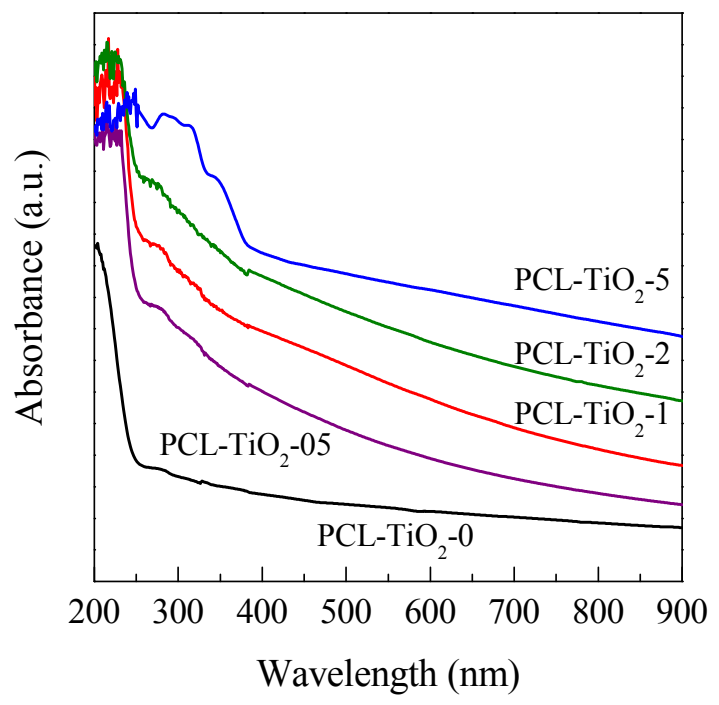

Performance of the PCL reference, as a control sample, and the PCL-TiO $2-05$, PCL-TiO $2-1$, PCL-TiO ${ }_{2}-2$ and $\mathrm{PCL}_{-} \mathrm{TiO}_{2}-5$ films were tested to analyze the biocidal properties of these organic-inorganic systems. Experiments measuring the UV-alone effect on the microorganism survival ratios were also run. Results are depicted in Figure 7 for the two different microorganisms employed: the Gram-negative Escherichia coli (E. coli) and Gram-positive Staphylococcus aureus (S. aureus) bacteria. These measurements intend to establish the potential of these nanocomposite films against pathogens involved in the contamination and/or deterioration of packaged foods $[5,42]$.

A first general point to stress out is that both control experiments (e.g., UV-alone and UV + PCL) produce only very moderate effects on the total log-reduction. The presence of $\mathrm{TiO}_{2}$ extremely affects the bio-killing action in the nanocomposite materials. A log-reduction ranging from 3 to 5.6 is observed, depending on $\mathrm{TiO}_{2}$ content at the end of the experiment against E. coli (e.g., 99.9\% to $99.999 \%$ killing), whereas it ranges from 4 to 5 for $S$. aureus. This killing level is commonly understood as being bactericidal and, as detailed elsewhere, is sufficient to maintain a good (human health) safety control, helping in eliminating the need for sterilization or other aggressive treatments of foods [43]. Concerning the optimum $\mathrm{TiO}_{2}$ loading within the nanocomposites, non-definitive conclusion can be reached, since Figure 7 provides evidence of a distinct trend observed after UV irradiation, depending on the microorganism analyzed. Then, an increasing log-reduction is seen for E. coli as $\mathrm{TiO}_{2}$ is raised in the nanocomposite, but $\mathrm{PCL}-\mathrm{TiO}_{2}-1, \mathrm{PCL}-\mathrm{TiO}_{2}-2$ and $\mathrm{PCL}-\mathrm{TiO}_{2}-5$ hybrids exhibit a similar biocidal behavior against $S$. aureus, this being better than that shown by the $\mathrm{PCL}^{-\mathrm{TiO}_{2}-05}$ specimen. The maximization of the bio-killing action is for E. coli somehow parallel to the morphological aspects (i.e., good dispersions and non-existence of agglomerates of large size) and the optical properties, both being relied on the correct handling of the matter-light interaction. It seems that an efficient charge carrier separation has been achieved upon the mixing of the polymer, and oxide 
components for samples having $\mathrm{TiO}_{2}$ content above $1 \mathrm{wt} \% \%$ are of particular importance. Holes should be preferentially located in the organic component after charge carrier separation [17], being thus able to interact with microorganisms without the need of a direct oxide-biological contact.

Figure 7. Survival curves after irradiation at $280 \mathrm{~nm}$ for two microorganisms (E. coli and $S$. aureus, top and bottom plots, respectively) as a function of the irradiation time for PCL- $\mathrm{TiO}_{2}-x$ and PCL control samples.
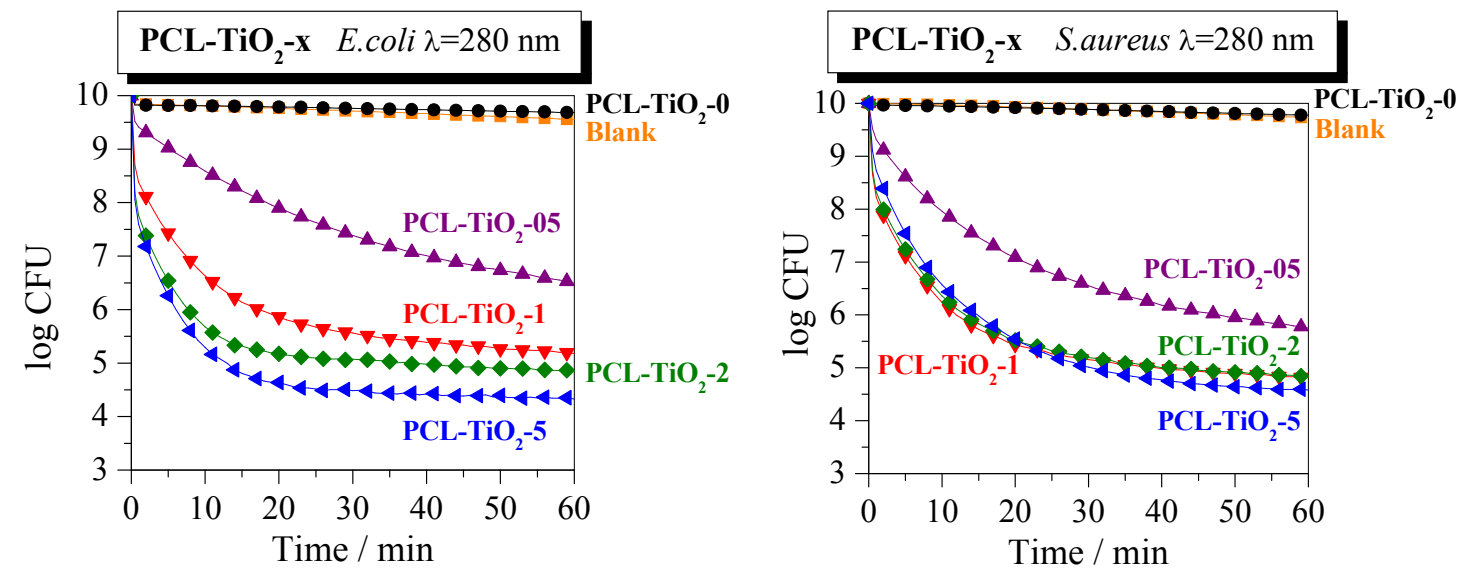

Comparison with previous results concerning the efficiency of inorganic/organic biocidal agents is easy in the case of the E. coli [44-50] and S. Aureus [51,52] microorganisms. There is also an important number of works devoted to both pathogens [53-59]. To make appropriate comparison of biocidal properties, we must consider at least three points: the first one relates to the rather different excitation energies and/or fluences (power $\times$ time) used in experiments with titania, as both influence significantly the results. The second concerns the state and nature of the biocidal agent; while certain biocidal agents, as $\mathrm{Ag}$, are typically released to the media, others, like $\mathrm{TiO}_{2}$, works by surface/near-surface contact and displays significant variability in efficiency while used as powders or immobilized in a support. As is well known, as a powder, it may present typically a one-fold order of magnitude higher activity (for example, in the case of E. coli) [60], due to the fact that nanoparticles in suspension/powders can be ingested by microorganisms via phagocytosis, causing rapid cellular damage in addition to that caused by photo-activity [44]. The third point is specific for the measurements of cell inactivation reaction rates, as they show a linear relationship with the initial bacteria concentration, a fact that must be taken into account when comparing results [61].

E. coli control and elimination have received a lot of attention as a general model system, with reports using $\mathrm{TiO}_{2}$ powders [44-48,53], immobilized/supported $\mathrm{TiO}_{2}$ on polymers (acetate; polystyrene, Plexiglas) $[49,54,55,60]$ or $\mathrm{Ag}[50,57,58]$ biocidal agents. Considering that our films contain a "immobilized" $\mathrm{TiO}_{2}$ oxide, the maximum log-reduction (5.6) obtained after $1 \mathrm{~h}$ of treatment further confirms the goodness of the nanocomposite films. Measurements using immobilized/supported $\mathrm{TiO}_{2}$ systems give values of $c a$. 5.4/2/1 log-reduction for 1.5/0.5/1 h of treatment [49,54,55]. To end, the comparison can be extended to Ag-based biocidal agents; while a general higher activity is observed for our system, we can make a direct, useful comparison with the immobilized AgION ${ }^{\circledR}$ on stainless steel, which showed a $5.6 \log$-reduction, but after $4 \mathrm{~h}$ of contact [58]. Overall, the situation is repeated when we consider the killing of $S$. aureus. Literature reports mentioned the use of $\mathrm{TiO}_{2}$ powders [53], 
immobilized/supported $\mathrm{TiO}_{2}$ on polymers (polystyrene, Plexiglas) [54,55] and $\mathrm{Ag}[51,57,58]$ systems, but also the use of negative air ions generated with the help of electrical fields [52]. None of them display comparable results in terms of efficiency or time response, this being particularly true for the immobilized $\mathrm{TiO}_{2}$ systems. An additional and illustrative comparison comes from the data reported by the use of different antibiotics/biocidals coating the EVOH polymer [59]. Only a powerful antibiotic, gatifloxacin, gives comparable results in terms of log-reduction, but for a certainly extended period of times $(24 \mathrm{~h})$, derived in the case of the antibiotic for its slow release from the polymer matrix. A recent investigation pointed out the bactericidal activities against these two microorganisms in the absence of light of titanium hydroxyl species generated by in situ sol-gel within polypropylene [62]. Authors postulated that these species participated to specific nanomaterial-cell interactions, and although cell death in the dark was less pronounced than in the light, titanium-based species caused oxidative stress under non-photocatalytic conditions.

Comparison with other systems previously prepared and analyzed by us indicates that $\mathrm{PCL}-\mathrm{TiO}_{2}-x$ nanocomposites behave under UV irradiation slightly better than those based on $\mathrm{EVOH}$ copolymer [17,63] and slightly worse than the ones prepared from isotactic polypropylene [11]. It should be commented that these last hybrids incorporated an interfacial agent to improve organic/inorganic contacts at interfaces, while those here analyzed and the ones prepared using EVOH as polymeric matrix are binary systems. On the other hand, the biocidal capabilities in the UV region were further improved in the EVOH based nanocomposites against E. coli after doping with Ag and $\mathrm{Zn}$ on the $\mathrm{TiO}_{2}$ inorganic component $[17,41,63]$. The purpose of doping was to be able to spread out the absorption light into the visible region of the electromagnetic spectrum, since, for instance, Ag exhibits a very intense localized surface plasmon (LSP) absorption band in the near-UV-visible region. Therefore, the potential of working under sunlight and/or diffuse artificial light, typical of human environments, without requiring UV excitation could be promoted. It was found that the antimicrobial performance of the $\mathrm{TiO}_{2}$-Ag films was maintained upon visible-light excitation $(500 \mathrm{~nm})$, although it was lowered compared with that presented by those $\mathrm{TiO}_{2}$-Ag films after UV irradiation. Nevertheless, this $\mathrm{TiO}_{2}-\mathrm{Ag}$ biocidal response was much higher than the modest performance of the $\mathrm{EVOH} / \mathrm{TiO}_{2}$ nanocomposites at $500 \mathrm{~nm}[17,41,63]$. These features observed in $\mathrm{TiO}_{2}-\mathrm{Ag}$ films were also found using $\mathrm{Zn}$ as dopant, while results after doping $\mathrm{TiO}_{2}$ with $\mathrm{Cu}$ [41] were similar to those displayed by $\mathrm{EVOH} / \mathrm{TiO}_{2}$ nanocomposites. The biocidal behavior of those nanocomposites was associated with the presence of true, new electronic states $[12,17,63]$, unequivocally ascribable to the nanocomposite system, as confirmed by photoluminescence. The samples here under study have been also exposed at $500 \mathrm{~nm}$ in order to establish a comparison with those aforementioned systems. Figure 8 shows the striking results found in these $\mathrm{PCL}^{-} \mathrm{TiO}_{2}-x$ specimens, since they display very significant biocidal properties against both microorganisms at $500 \mathrm{~nm}$. The ${\mathrm{PCL}-\mathrm{TiO}_{2}-5}^{-5}$ system is the optimum one for killing E. coli, whereas $\mathrm{PCL}-\mathrm{TiO}_{2}-2$ exhibits the optimized response against $S$. aureus. The reason behind this extraordinary behavior upon visible-light excitation is not yet well understood, and further analyses are required for a complete comprehension. 
Figure 8. Survival curves after irradiation at $500 \mathrm{~nm}$ for two microorganisms (E. coli and $S$. aureus, top and bottom plots, respectively) as a function of the irradiation time for PCL-TiO $2-x$ and PCL control samples.
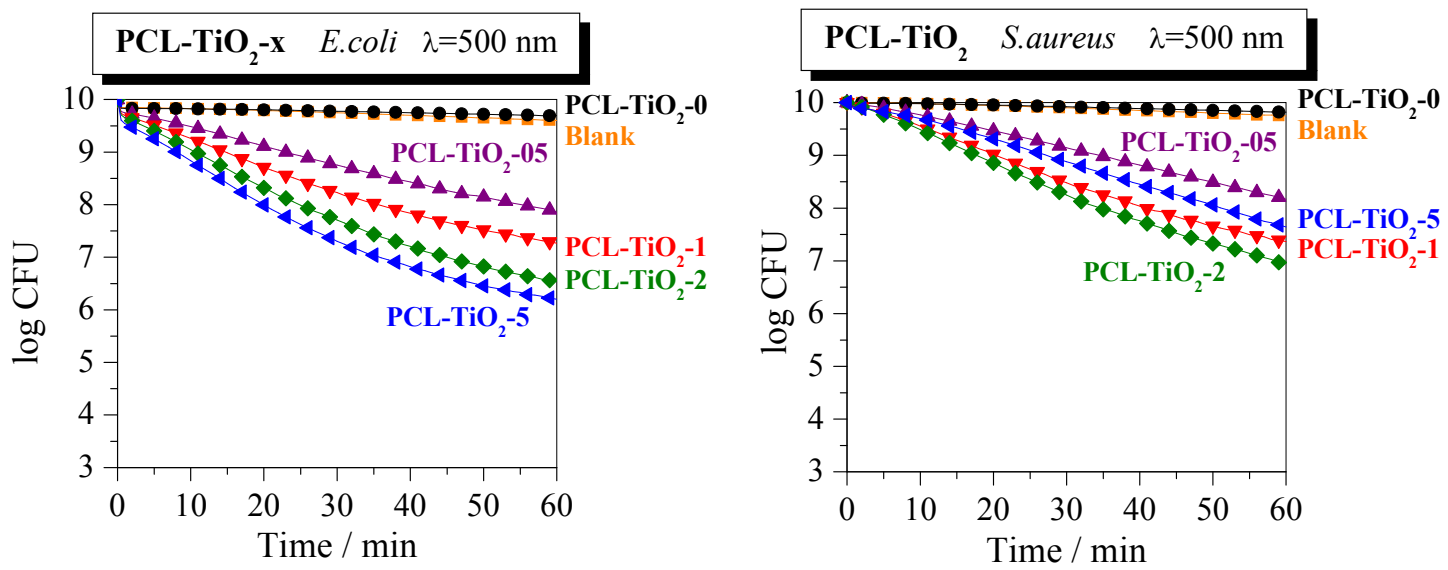

\section{Experimental Section}

Nanocomposite preparation: The $\mathrm{TiO}_{2}$ component was prepared using a microemulsion synthetic route and calcined at $450{ }^{\circ} \mathrm{C}$ (characteristic primary particle size below $10 \mathrm{~nm}$ ) [64]. These novel materials were prepared through melt processing at $140{ }^{\circ} \mathrm{C}$ and at $100 \mathrm{rpm}$ for $15 \mathrm{~min}$ in a miniextruder Thermo Scientific Haake Minilab. Previous to this, nanoparticles and PCL were sonicated (Sonics VC505) and stirred to homogenize the batch. After their mixing, specimens were obtained as films by compression molding in a Collin press between hot plates $\left(120^{\circ} \mathrm{C}\right)$ at a pressure of $1.5 \mathrm{MPa}$ for $5 \mathrm{~min}$. A quench was applied to the different films from the melt to room temperature. The resulting nanocomposites were labeled as $\mathrm{PCL}-\mathrm{TiO}_{2}-x$, where $x$ corresponds to the weight percentage of titania content.

Nanocomposites characterization: Transmission electron microscopy (TEM) was performed at room temperature in a $200 \mathrm{kV}$ JEM-2100 JEOL microscope to analyze material homogeneity. Samples were cut in thin sections $(40 \mathrm{~nm})$ by cryo-ultramicrotomy (Leica EM UC6). Specimens were then picked up on copper grids. Wide and small angle X-ray scattering, WAXS and SAXS, respectively, experiments employing synchrotron radiation $(\lambda=0.150 \mathrm{~nm})$ were performed at the beamline A2 at HASYLAB (Hamburg, Germany). A MARCCD detector was used for data acquisition, sited at a distance from the sample of 25 and $265 \mathrm{~cm}$, for WAXS and SAXS measurements, respectively. Calibration was performed in the WAXS region with the distinct diffractions of a triclinic semicrystalline poly(ethylene terephthalate) (PET) sample, and the SAXS one was calibrated with the different orders of the long spacing of a rat-tail cornea $(\lambda=65 \mathrm{~nm})$. The two-dimensional X-ray patterns were processed with the A2tool program, developed to support beamline A2 data processing. The profiles were normalized to the primary beam intensity and the background from an empty sample was subtracted. All experiments comprise the heating of samples from 20 up to $76{ }^{\circ} \mathrm{C}$ at $8{ }^{\circ} \mathrm{C} / \mathrm{min}$. The data acquisition was done in frames of $15 \mathrm{~s}$. The phase transitions were analyzed by differential scanning calorimetry measurements performed in a TA Instruments TA2000 calorimeter connected to a cooling system and calibrated with different standards. Samples ( $\sim 5 \mathrm{mg})$ were scanned from -80 to $90{ }^{\circ} \mathrm{C}$ at $10{ }^{\circ} \mathrm{C} / \mathrm{min}$ under dry nitrogen $\left(50 \mathrm{~cm}^{3} / \mathrm{min}\right)$. The weight loss was estimated by 
thermogravimetry using TA Instruments TGA Q500 equipment working under inert nitrogen and air atmospheres $\left(90 \mathrm{~cm}^{3} / \mathrm{min}\right)$. The equipment was calibrated according to standard protocols. The sample weights ranged from 4 to $6 \mathrm{mg}$, and the heating rate was $10^{\circ} \mathrm{C} / \mathrm{min}$.

Microbiological tests: The microorganisms used in this study include E. coli $1337-\mathrm{H}$ and $S$. aureus 1341-H and were obtained from the German Collection of Microorganisms and Cell Cultures (DSMZ, Braunschweig, Germany) and cultured and maintained according to the recommendations of the suppliers [65]. Briefly, E. coli 1337-H and S. aureus 1341-H were grown in Luria-Bertani (LB) medium at $37{ }^{\circ} \mathrm{C}$ using $100 \mathrm{~mL}$ flasks filled with $10 \mathrm{~mL}$ of the respective medium and subsequently used for photochemical cell viability assays. To study the antimicrobial activity of films, a suspension containing $10 \mu \mathrm{L}$ of microbial cells (ca. $\left.10^{9} \mathrm{CFU} / \mathrm{mL}\right)$ suspended in $1 \mathrm{~mL}$ broth solution was made [66]. Aliquots of $1 \mathrm{~mL}$ from these suspensions were added to a $4 \mathrm{~mL}$ quartz cubic cell containing $1 \mathrm{~mL}$ of sterilized water and the corresponding film under continuous stirring. The film-cell slurry was placed in the UV spectrometer chamber (UVIKON 930) and irradiated with a light at 280 (UV) and 500 (visible) $\mathrm{nm}$ for different time periods. The four nanocomposite samples $\left(\mathrm{PCL}-\mathrm{TiO}_{2}-x\right)$ together with two blanks (i.e., PCL + irradiation and irradiation alone) were measured using the same bacterium inoculum for each microorganism tested. As demonstrated by blank experiments, care was put of using a sub-lethal, maximum radiation energy fluence of $c a .1 \mathrm{~kJ} / \mathrm{m}^{2}$ throughout the study. After irradiation and for different time intervals, aliquots of $100 \mu \mathrm{L}$ were transferred to a $10 \mathrm{~mL}$ LB broth test tube. The order of cell dilution at this stage was $10^{-2}$. Loss of viability after each exposure time was determined by the viable count procedure on Luria Bertani agar plates after serial dilution $\left(10^{-2}\right.$ to $\left.10^{-5}\right)$. All plates were incubated at $37{ }^{\circ} \mathrm{C}$ for $24 \mathrm{~h}$ prior to enumeration. A minimum of three experimental runs were performed to determine antimicrobial activity; this leads to a standard error of $\pm 0.1 \log \mathrm{CFU} / \mathrm{mL}$ units in the reported results.

\section{Conclusions}

The characterization of $\mathrm{PCL}-\mathrm{TiO}_{2}-x$ nanocomposites with different anatase $\mathrm{TiO}_{2}$ contents ranging from 0 to 5 wt.\% provides evidence of the nanometric dispersion of the oxide component on the polymeric matrix, with average aggregates well below $100 \mathrm{~nm}$. Moreover, dependence of crystalline characteristics is subtle on anatase contents in terms of crystallinity degree, long spacing, most probable crystal size and melting temperature. Concerning the melting process, the PCL-based specimens must have an identical and well-defined thermal protocol in order to obtain reproducible and reliable results, since PCL macrochains evolve with time, leading to multiple melting stages, due to their low glass transition temperature. These multiple melting processes are ascribed to successive melting-recrystallization phenomena. Moreover, an evident nucleating effect is observed during crystallization process because of the $\mathrm{TiO}_{2}$ nanoparticle presence.

On the other hand, incorporation of $\mathrm{TiO}_{2}$ nanoparticles does not change much PCL degradability independently of the environment used, either inert or oxidant one. A good agreement is found when comparing the averaged values with the theoretical loadings from the residual mass at the end of the experiments.

The absorption profiles undergo important changes in these nanocomposites when compared with that exhibited by PCL matrix: enhancement of signal intensity in the UV-A and visible ranges and 
indication of the characteristic oxide band gap, this last feature only clearly distinguishable in the sample with the highest $\mathrm{TiO}_{2}$ content $\left(\mathrm{PCL}-\mathrm{TiO}_{2}-5\right)$.

The presence of $\mathrm{TiO}_{2}$ extremely affects the bio-killing action in the nanocomposite materials under UV irradiation. A log-reduction ranging from 3 to 5.6 is observed depending on $\mathrm{TiO}_{2}$ content at the end of the experiments against E. coli, whereas it is ranging from four to five for $S$. aureus. An evident dependence on $\mathrm{TiO}_{2}$ content is seen against E. coli, although behavior is similar for the distinct nanocomposites above 0.5 wt.\% against $S$. aureus. Nevertheless, the most remarkable and extraordinary result found in these nanocomposites is their biocidal response at $500 \mathrm{~nm}$ against both microorganisms analyzed. The PCL- $\mathrm{TiO}_{2}-5$ system is the optimum one for killing E. coli, whereas PCL-TiO $2-2$ exhibits the optimized response against $S$. aureus.

\section{Acknowledgments}

Muñoz-Bonilla and A. Kubacka acknowledge MICINN for financial supports (Juan de la Cierva and Ramón y Cajal postdoctoral contracts, respectively). Funding of MICINN is acknowledged (CTQ2010-14872/BQU, MAT2010-17016, MAT2010-19883, PLE2009-0037, PRI-PIBJP-2011-0914). The synchrotron work leading to these results has received funding from the European Community's Seventh Framework Programme (FP7/2007-2013) under grant agreement $n^{\circ} 312284$.

\section{Conflict of Interest}

The authors declare no conflict of interest.

\section{References}

1. John, J.; Mani, R.; Battacharya, M. Evaluation compatibility and properties of biodegradable polyester blends. J. Polym. Sci. Polym. Chem. 2002, 40, 2003-2014.

2. Cao, A.; Okamura, T.; Ishiguro, C.; Nakayama, K.; Inoue, Y.; Masuda, T. Studies on synthesis and physical characteristics of biodegradable aliphatic poly (butylene succinate-co-e-caprolactone). Polymer 2002, 43, 671-679.

3. Sarasam, A.R.; Samli, A.I.; Hess, L.; Ihnat, M.A.; Madihally, S.V. Blending chitosan with polycaprolactone: Porous scaffolds and toxicity. Macromol. Biosci. 2007, 7, 1160-1167.

4. Nohynek, G.J.; Lademann, J.; Ribaud, C.; Roberts, M.S. Grey goo on the skin? Nanotechnology, cosmetic and sunscreen safety. Crit. Rev. Toxicol. 2007, 37, 251-277.

5. Appendini, P.; Hotchkiss, J.H. Review of antimicrobial food packaging. Innov. Food Sci. Emerg. Technol. 2002, 3, 113-126.

6. Jacoby, W.A.; Maness, P.C.; Wolfrum, E.J.; Blake, D.M.; Fennell, J.A. Mineralization of bacterial cell mass on a photocatalytic surface in air. Environ. Sci. Technol. 1998, 32, 2650-2653.

7. Brook, L.A.; Evans, P.; Foster, H.A.; Pemble, M.E.; Steele, A.; Sheel, D.W.; Yates, H.M. Highly bioactive silver and silver/titania composite films grown by chemical vapour deposition. J. Photochem. Photobiol. A 2007, 187, 53-63.

8. Dietbol, U. The surface science of $\mathrm{TiO}_{2}$. Surf. Sci. Rep. 2003, 48, 53-229. 
9. Fernández-García, M.; Martínez-Arias, A.; Hanson, J.C.; Rodríguez, J.A. Nanostructured oxides in chemistry: Characterization and properties. Chem. Rev. 2004, 104, 4063-4104.

10. Kubacka, A.; Serrano, C.; Ferrer, M.; Lünsdorf, H.; Bielecki, P.; Cerrada, M.L.; Fernández-García, M.; Fernández-García, M. High performance dual action polymer $\mathrm{TiO}_{2}$ nanocomposite films via melting processing. Nano Lett. 2007, 7, 2529-2534.

11. Kubacka, A.; Cerrada, M.L.; Serrano, C.; Fernández-García, M.; Ferrer, M.; Fernández-García, M. Light-driven novel properties of $\mathrm{TiO}_{2}$-modified Polypropylene-based nanocomposite films. J. Nanosci. Nanotech. 2008, 8, 3241-3246.

12. Cerrada, M.L.; Serrano, C.; Sánchez-Chaves, M.; Fernández-García, M.; Fernández-Martín, F.; de Andrés, A.; Jiménez Riobóo, R.J.; Kubacka, A.; Ferrer, M.; Fernández-García, M. Self-sterilized EVOH-TiO 2 nanocomposites: Effect of $\mathrm{TiO}_{2}$ content on biocidal properties. Adv. Funct. Mater. 2008, 18, 1949-1960.

13. Cerrada, M.L.; Serrano, C.; Sánchez-Chaves, M.; Fernández-García, M.; de Andrés, M.A.; Jiménez Riobóo, R.J.; Fernández-Martín, F.; Kubacka, A.; Ferrer, M.; Fernández-García, M. Biocidal capability optimization in organic inorganic nanocomposites based on titania. Environ. Sci. Techn. 2009, 43, 1630-1634.

14. Gómez-Romero, P.; Sánchez, C. Functional Hybrid Materials; Wiley-Interscience: New York, NY, USA, 2004.

15. Sanchez, C.; Julián, B.; Belleiville, P.; Popall, M. Applications of hybrid organic-inorganic nanocomposites. J. Mater. Chem. 2005, 15, 3559-3592.

16. Kubacka, A.; Ferrer, M.; Cerrada, M.L.; Serrano, C.; Sánchez-Chaves, M.; Fernández-García, M.; de Andrés, A.; Jiménez Riobóo, R.J.; Fernández-Martín, F.; Fernández-García, M. Boosting $\mathrm{TiO}_{2}$-anatase antimicrobial activity: Polymer-oxide thin films. Appl. Catal. B Environ. 2009, 89, 441-447.

17. Kubacka, A.; Ferrer, M.; Fernández-García, M.; Serrano, C.; Cerrada, M.L.; Fernández-García, M. Tailoring polymer- $\mathrm{TiO}_{2}$ properties by presence of metal $(\mathrm{Ag}, \mathrm{Cu}, \mathrm{Zn})$ species: Optimization of antimicrobial properties. Appl. Catal. B Environ. 2011, 104, 346-352.

18. Hu, H.; Dorset, D.L. Crystal structure of poly(E-caprolactone). Macromolecules 1990, 23, 4604-4607.

19. Bahloul, W.; Bounor-Legaré, V.; David, L.; Cassagnau, P. Morphology and viscoelasticity of $\mathrm{PP} / \mathrm{TiO}_{2}$ nanocomposites prepared by in situ sol-gel method. J. Polym. Sci. Part B Polym. Phys. 2010, 48, 1213-1222.

20. Baltá-Calleja, F.J.; Vonk, C.G. X-ray Scattering of Synthetic Polymers; Elsevier: Amsterdam, The Netherlands, 1989.

21. Ryan, A.J.; Stanford, J.L.; Bras, W.; Nye, T.M.W. A synchrotron X-ray study of melting and recrystallization in isotactic polypropylene. Polymer 1997, 38, 759-768.

22. Crist, B. Small-angle X-ray scattering and polymer melting: A model study. J. Polym. Sci. Part B Polym. Phys. 2001, 39, 2454-2460.

23. Lee, Y.; Porter, R.S.; Lin, J.S. On the double-melting behaviour of poly (ether ether ketone). Macromolecules 1989, 22, 1756-1760. 
24. Cerrada, M.L.; Benavente, R.; Pérez, E. Crystalline structure and viscoelastic behavior in composites of a metallocenic ethylene-1-octene copolymer and glass fiber. Macromol. Chem. Phys. 2002, 203, 718-726.

25. Arranz-Andrés, J.; Peña, B.; Benavente, R.; Pérez, E.; Cerrada. M.L. Influence of isotacticity and molecular weight on the properties of metallocenic isotactic polypropylene. Eur. Polym. J. 2007, 43, 2357-2370.

26. López-Majada, J.M.; Palza, H.; Guevara, J.L.; Quijada, R.; Martínez, M.C.; Benavente, R.; Pereña, J.M.; Pérez, E.; Cerrada. M.L. Metallocenic copolymers of propene and 1 hexene: Influence of comonomer content and thermal history on the structure and mechanical properties. J. Polym. Sci. Part B Polym. Phys. 2006, 44, 1253-1267.

27. Bassett, D.C.; Olley, R.H.; Al Raheil, I.A.M. On isolated lamellae of melt-crystallized polyethylene. Polymer 1988, 29, 1745-1754.

28. Arranz-Andrés, J.; Benavente, R.; Ribeiro, M.R.; Pérez, E.; Cerrada. M.L. Evolution of a metallocenic sPP with time: Changes in crystalline content and enthalpic relaxation. Macromol. Chem. Phys. 2006, 207, 1564-1574.

29. Arranz-Andrés, J.; Benavente, R.; Pérez, E.; Cerrada. M.L. Structure and mechanical behavior of the mesomorphic form in a propylene b EPR copolymer and its comparison with other thermal treatments. Polym. J. 2003, 35, 766-777.

30. Krache, R.; Benavente, R.; López-Majada, J.M.; Pereña, J.M.; Cerrada, M.L.; Pérez, E. Competition between alpha, beta and gamma polymorphs in a beta-nucleated metallocene isotactic polypropylene. Macromolecules 2007, 40, 6871-6878.

31. Cerrada, M.L.; Polo-Corpa, M.J.; Benavente, R.; Pérez, E.; Velilla, T.; Quijada. R. Formation of the new trigonal polymorph in iPP-1-Hexene copolymers. Competition with the mesomorphic phase. Macromolecules 2009, 42, 702-708.

32. Pérez, E.; Gómez-Elvira, J.M.; Benavente, R.; Cerrada, M.L. Tailoring the formation rate of the mesophase in random propylene-co-1-pentene copolymers. Macromolecules 2012, 45, 6481-6490.

33. Crescenzi, V.; Manzini, G.; Calzolari, G.; Borri, C. Thermodynamics of fusion of poly- $\beta$-propiolactone and poly- $\varepsilon$-caprolactone. comparative analysis of the melting of aliphatic polylactone and polyester chains. Eur. Polym. J. 1972, 8, 449-463.

34. Nakagawa, S.; Kadena, K.; Ishizone, T.; Nojima, S.; Shimizu, T.; Yamaguchi, K.; Nakahama, S. Crystallization behavior and crystal orientation of poly( $\varepsilon$-caprolactone) homopolymers confined in nanocylinders: Effects of nanocylinder dimension. Macromolecules 2012, 45, 1892-1900.

35. Matyi, R.J.; Schwartz, L.H.; Butt, J.B. Particle size, particle size distribution, and related measurements of supported metal catalysts. Catal. Rev. Sci. Eng. 1987, 29, 41-99.

36. Arranz-Andrés, J.; Pulido-González, N.; Marín, P.; Aragón, A.; Cerrada. M.L. Electromagnetic shielding features in lightweight PVDF aluminum based nanocomposites. Prog. Electromagn. Res. B 2013, 48, 175-196.

37. Cerrada, M.L.; Pérez, E.; Lourenço, J.P.; Campos, J.M.; Ribeiro, M.R. Hybrid HDPE/MCM-41 nanocomposites: Crystalline structure and viscoelastic behaviour. Micropor. Mesopor. Mat. 2010, $130,215-223$.

38. Arranz-Andrés, J.; Pérez, E.; Cerrada, M.L. Hybrids based on poly(vinylidene fluoride) and $\mathrm{Cu}$ nanoparticles: Characterization and EMI shielding. Eur. Polym. J. 2012, 48, 1160-1168. 
39. Serrano. C. Oxide-polymer antimicrobial nanocomposites: Chemical-physics characterization and biocidal response. Ph.D. Thesis, Univesidad Complutense de Madrid, Madrid, Spain, 2011.

40. Serrano, C.; Cerrada, M.L.; Fernández-García, M.; Ressia, J.; Vallés, E.M. Rheological and structural details of biocidal $\mathrm{iPP}^{-\mathrm{TiO}_{2}}$ nanocomposites. Eur. Polym. J. 2012, 48, 586-596.

41. Kubacka, A.; Ferrer, M.; Fernández-García, M. Kinetics of photocatalytic disinfection in $\mathrm{TiO}_{2}$-containing polymer thin films. Appl. Catal. B Environ. 2012, 121-122, 230-238.

42. Blackburn, C. Food Spoilage Microorganisms; Woodhead Publishing Ltd.: Cambridge, UK, 2006.

43. Gunndermann, K.O.; Ruden, H.; Sunntag, H.G. Lehrbuch der Hygiene; Ficher: Stuttgart, Germany \& New York, NY, USA, 1991.

44. Huang, Z.; Maness, P.C.; Blake, D.M.; Wolfrum, E.J.; Smolinski, S.L.; Jacoby, W.A. Bactericidal mode of titanium dioxide photocatalysis. J. Photochem. Photobiol. A 2000, 130, 163-170.

45. Ibañez, J.A.; Litter, M.I.; Pizarro, R.A. Photocatalytic bactericidal effect of $\mathrm{TiO}_{2}$ on enterobacter cloacae: Comparative study with other Gram (-) bacteria. J. Photochem. Photobiol. A 2003, 157, 81-85.

46. Robertson, J.M.C.; Robertson, P.K.; Lawton, L.A. A comparison of the effectiveness of $\mathrm{TiO}_{2}$ photocatalysis and UVA photolysis for the destruction of three pathogenic micro-organisms. J. Photochem. Photobiol. A 2005, 175, 51-56.

47. Cho, M.; Chung, H.; Choi, W.; Yoon, J. Linear correlation between inactivation of E. coli and OH radical concentration in $\mathrm{TiO}_{2}$ photocatalytic disinfection. Water Res. 2004, 38, 1069-1077.

48. Joo, J.; Kwon, S.G.; Yu, T.; Cho, M.; Lee, J.; Yoon, J.; Hyeon, T. Large-scale synthesis of $\mathrm{TiO}_{2}$ nanorods via nonhydrolytic sol-gel ester elimination reaction and their application to photocatalytic inactivation of E. coli. J. Phys. Chem. B 2005, 109, 15297-15302.

49. Lonnen, J.; Kilvington, S.; Al-Touati, F.; McGuigan, K.G. Solar and photocatalytic disinfection of protozoan, fungal and bacterial microbes in drinking water. Water Res. 2005, 39, 877-883.

50. You, K.Y.; Byeon, J.H.; Park, J.H.; Hwang, J. Susceptibility constants of Escherichia coli and Bacillus subtilis to silver and copper nanoparticles. Sci. Total Environ. 2007, 373, 572-575.

51. Ho, C.; Tobis, J.; Sprich, C.; Thomann, R.; Tiller, J.C. Nanoseparated polymeric networks with multiple antimicrobial properties. Adv. Mater. 2004, 16, 957-961.

52. Arnol, J.W.; Boothe, D.H.; Mitatell, B.W. Use of negative air ionization for reducing bacterial pathogens and spores on stainless steel surfaces. J. Appl. Poult. Res. 2004, 13, 200-206.

53. Seven, O.; Dinder, B.; Aydemir, S.; Metin, D.; Ozinel, M.A.; Icli, S. Solar photocatalytic disinfection of a group of bacteria and fungi aqueous suspensions with $\mathrm{TiO}_{2}, \mathrm{ZnO}$ and Sahara desert dust. J. Photochem. Photobiol. A 2004, 165, 103-107.

54. Kuhn, K.P.; Chaberny, I.F.; Massholder, K.; Stickler, M.; Benz, V.W.; Sonnatg, H.-G.; Erdinger, L. Disinfection of surfaces by photocatalytic oxidation with titanium dioxide and UVA light. Chemosphere 2003, 53, 71-77.

55. Wang, Z.; Li, G.; Peng, H.; Zhang, Z.; Wang, X. Study on novel antibacterial high impact polystyrene/ $/ \mathrm{TiO}_{2}$ nanocomposites. J. Mater. Sci. 2005, 40, 6433-6438.

56. Page, K.; Palgrave, R.G.; Parkin, P.; Wilson, M.; Sarin, S.L.P.; Chadwick, A.V. Titania and silver-titania composite films on glass-potent antimicrobial coatings. J. Mater. Sci. 2007, 17, 95-104.

57. Vohra, A.; Goswami, D.Y.; Deshpande, D.A.; Block, S.S. Enhanced photocatalytic disinfection of indoor air. Appl. Catal. B 2006, 65, 57-65. 
58. Cowan, M.M.; Abshire, K.Z.; Houk, S.L.; Evans, S.M. Antimicrobial efficacy of a silver-zeolite matrix coating on stainless steel. J. Ind. Microbiol. Biotechnol. 2003, 30, 102-106.

59. Oyama, A.; Yokoyama, Y.; Uchida, M.; Ito, A. The formation of an antibacterial agent-apatite composite coating on a polymer surface using a metastable calcium phosphate solution. Biomaterials 2006, 27, 3295-3303.

60. Rincón, A.G.; Pulgarin, C. Photocatalytical inactivation of E. coli: Effect of (continuous-intermittent) light intensity and of (suspended-fixed) $\mathrm{TiO}_{2}$ concentration. Appl. Catal. B 2003, 44, 263-284.

61. Rincón, A.G.; Pulgarin, C. Bactericidal action of illuminated $\mathrm{TiO}_{2}$ on pure Escherichia coli and natural bacterial consortia: Post-irradiation events in the dark and assessment of the effective disinfection time. Appl. Catal. B 2004, 49, 99-112.

62. Bahloul, W.; Mélisa, F.; Bounor-Legaréa, V.; Cassagnau, P. Structural characterisation and antibacterial activity of $\mathrm{PP} / \mathrm{TiO}_{2}$ nanocomposites prepared by an in situ sol-gel method. Mat. Chem. Phys. 2012, 134, 399-406.

63. Kubacka, A.; Cerrada, M.L.; Serrano, C.; Fernández-García, M.; Ferrer, M.; Fernández-García, M. Plasmonic nanoparticle/polymer nanocomposites with enhanced photocatalytic antimicrobial properties. J. Phys. Chem. C 2009, 113, 9182-9190.

64. Fernández-García, M.; Wang, X.; Belver, C.; Hanson, J.C.; Rodriguez, J.A. Anatase-TiO 2 nanomaterials: Morphological/size dependence of the crystallization and phase behavior phenomena. J. Phys. Chem. C 2007, 111, 674-682.

65. Sambrook, J.; Fritsch, E.F.; Maniatis, T. Molecular Cloning: A Laboratory Manual, 2nd ed.; Cold Spring Harbor Laboratory Press: New York, NY, USA, 1989.

66. Ferrer, M.; Soliveri, J.; Plou, F.J.; López-Cortés, N.; Reyes-Duarte, D.; Christensen, M.; Copa-Patiño, J.L.; Ballesteros, A. Synthesis of sugar esters in solvent mixtures by lipases from thermomyces lanuginosus and Candida antarctica $\mathrm{B}$, and their antimicrobial properties. Enzyme Microb. Technol. 2005, 36, 391-398.

(C) 2013 by the authors; licensee MDPI, Basel, Switzerland. This article is an open access article distributed under the terms and conditions of the Creative Commons Attribution license (http://creativecommons.org/licenses/by/3.0/). 